flaccid paraplegia will often walk perfectly after an hour's treatment, whereas a man with a slight functional limp will need a re-education lasting for days or even weeks.

$$
\text { Tremors, Fits, \&c. }
$$

We have given a detailed account of the treatment of deafness, mutism, and paralysis because these cases are so easily curable with rapid suggestive and re-educative measures. They are all due to the absence or diminished activity of a normal function, and the treatment has only to recall this function to the patient's consciousness. Fortunately these cases form a large percentage of the hysterical war neuroses. There is, however, a group of cases in which the treatment is often successful, but by no means invariably. These cases depend not so much on the absence of a normal function as on its excessive and disordered activity. Functional tremors and incoördination, choreiform movements, and tic-like spasms are examples of this class, and we might include hysterical fits and even the stammering and explosive type of speech. Functional tremors are sometimes very easily cured by a little suggestive faradism, and fits may be stopped temporarily at least by suggestive measures. The patient is induced to have a fit by assuring him that he will do so when an electric current is applied to his forehead, and the fit is checked by supraorbital pressure or faradism to some other part of the body. The patient is then told that his fits are not epileptic and that they have been cured. As a rule he will have no more fits as long as he is in hospital, but he may relapse outside, and we know of several cases where this has happened. Indeed, the method is probably more valuable as an aid to diagnosis than to treatment.

Involuntary movements and hysterical chorea may yield to rapid suggestive methods, but isolation is a more reliable form of treatment, although it is at the best a slow process.

Functional contractures deserve a place by themselves. When they are truly hysterical they will usually yield at once to suggestive faradism with a moderately strong current. But it is sometimes extremely difficult to make certain that the condition has not some organic basis. Babinski and Froment have collected a number of cases described as reflex nervous disorders and having an organic origin, although they show a superficial resemblance to the hysterical contractures. $^{5}$ These cases are generally intractable, and so far no line of treatment has been found to have much effect on them. We have seen four or five cases which could be included in this category, and in them suggestive treatment was certainly quite ineffective.

For the sake of completeness we should mention a method of suggestion which is often employed with good results. This consists in anæsthetising the patient and making the necessary suggestions to him as he is going under or coming round from the anæsthetic. To a certain extent the process may be compared with hypnotism in that the suggestions are made at a time when the critical faculties of the patient are dulled; but the main advantage of the method lies in the fact that in the stage of excitement the patient will struggle, cry out, \&c., and that he will often regain consciousness whilst he is in the act of moving the arm which was formerly paralysed or using the voice which was formerly dumb. The method demands an anæsthetist who will be able to produce a long excitement stage, and the results are to some extent a matter of luck. This furnishes the chief objection to the method, for if it fails the patient will have some excuse for taking a gloomy view of his case, and he will be naturally sceptical of less heroic methods. However, we have little direct experience of the method, as we have not found it necessary to employ it.

\section{Prognosis and After-treatment.}

The treatment of a functional case does not end at the moment when the disability has been cured, and we have always to determine how much the patient may be safely called upon to do without fear of a relapse. This will depend on how far the underlying mental condition is a permanent state and how great a strain was necessary to lead to the development of the symptoms. If the patient gives a history showing pronounced mental instability or previous functional troubles before the war, and if he has lost the use of his legs after a few days in the trenches, it is

5 Babinski et Froment: Hystérie-Pithiatisme et Troubles Nerveux d'Ordre Réflexe. Masson et Cie. 1917.

clear that he will never be of the least value at the front, and he is probably best employed in a labour unit at home or on sedentary work. If he has served several months in the fighting line, and has then lost his voice after a week without sleep and a severe bombardment, he will often be perfectly fit again after a short rest, and he will show only the slightest signs of the hysterical temperament. He may relapse under an equally severe strain, but if his cure has been rapid and complete on the first occasion he will have less reason to fear a relapse and to regard a temporary loss of speech as a serious and intractable condition. It is another matter if he has been allowed to remain dumb for six months in hospital, for in this case he will have every reason to regard himself as the victim of a severe form of "shell shock," and he will probably be quite unfit for service in the fighting line.

In all cases a thorough examination of the past history and mental condition must be made before we can decide what form of service will be most advantageous to the patient and to the nation. In the more intractable conditions-tics, convulsions, \&c.--the patient may be able to do some useful work with a labour unit, but it is often better for all concerned to return him to civilian life.

In conclusion, we wish to express our thanks to the medical and surgical staff of the National Hospital, Queen. square, and to Lieutenant-Colonel W. Turner, offeer in charge of the Connaught Hospital, Aldershot, for permission to publish these notes.

\title{
CHYLO-HAMOTHORAX FROM WOUNDS INVOLVING THE THORACIC DUCT.
}

BY T. R. ELLIOTT, F.R.C.P.LOND., F.R.S., LIEUTENANT-COLONEL, R.A.M.C. AND

HERBERT HENRY, M.D. LOND., CaPTAIN, R.A.M.C.

Wrien a fluid obtained by exploratory puncture of the chest seems to be "frankly purulent" to the naked eye one is apt to assume that this appearance is sufficient proof that an empjema is present and that rib resection is justified without any further microscopic study of the specimen.

In nearly all such cases the presumption that infection exists is true, but occasionally a rare example may be encountered in which the thoracic duct has been wounded in the chest without the associated injuries being at once fatal, and then the milky chyle will leak into the effused blood and produce a combination mimicking that of a pyo-hæmothorax so closely that most surgeons would be deceived by it.

The first case quoted in this paper was one in which the error was not avoided and the medical officer was misled by the appearance of the fluid into performing an operation for drainage of the pleural cavity. The patient recovered, but his convalescence was dated by months instead of by weeks in consequence of the mistake. In the second case the character of the fiuid was guessed to be chylous and proved to be so before anything was done. But unfortunately the effusion had been infected by the shell fragment which caused the wound and drainage was unavoidable and was followed by death.

The error can only be avoided by holding fast at all times to the general clinical rule: "That drainage of a chest after gunshot wound should never be undertaken except apon bacteriological proof of infection in the fluid withdrawn at exploration, or upon the recognition of an offensive smell in the latter." The naked-eye appearance of any fluid may be entirely misleading, as hopelessly, though not so frequently, as is the clinical judgment of a chest wound before exploration is made.

At base hospitals these cases of chylo-hæmothorax must be very few. The two that are described from our own experience did actually occur in the same hospital within a month of one another, but they are the only two that we have seen out of a total of 600 samples of hæmothorax fluid that were examined by us in the laboratory; and this laboratory figure covers a clinical experience of far more than a thousand chest wounds. But the occurrence of a chylous effusion would not appear to be so rare as this, if it were expressed as a percentage of all large effusions on the 
left side of the chest. The possibility is certainly a practical point which deserves to be borne in mind when dealing with big traumatic effusions in the left pleural cavity.

$$
\text { Diagnosis. }
$$

There are several points which characterise a chylous leak into a hæmothorax.

1. The collection of fluid is on the left side.

2. The effusion continues to increase steadily and rapidly on the third and fourth day, causing progressive cardiac and respiratory embarrassment. Such an increase is rarely seen with an ordinary sterile hæmothorax, where the bleeding is either fatal or ceases in the first 24 hours. It may, however, occur as the result of infection of a hæmothorax. A chylous effusion, even if infected, will not be accompanied by high fever because the patient's nutrition is profoundly impaired; whereas sepsis in a simple hæmothorax generally causes a high temperature.

3. Exploration discovers a fluid which appears to be heavily loaded with pus. If this appearance is seen in a large collection of fluid early in the first week after the wound, it is almost certain that it must not be ascribed to pus, because the processes of pleural suppuration following upon sepsis in a hæmothorax take many days before they can produce an abundant pleural exudate.

4. The fluid is opaque, and its colour will vary from red to pink or creamy-grey in accordance with the proportion of commingled blood. In the two cases that are described below the fluid did not clot after withdrawal from the chest, presumably because its fibrin was being separated by coagulation within the chest as fast as the chyle escaped from the duct.

5. On centrifugalisation a deposit of red cells is thrown down, leaving a supernatant opaque milky fluid whose creamy-white colour contrasts brilliantly with the red band below. Under the microscope the milky fluid is seen to be filled with small fat globules, which are immediately soluble in ether. A few mononuclear leucocytes are scattered among these fat globules.

\section{Anatomy of the Lesion.}

The cervical part of the thoracic duct, or one of its branches, has occasionally chanced to be injured in the surgical operations of civil life when extensive dissections are being made in the root of the neck. The records of such cases have been fully collected in a recent paper by \$. Harrison. ${ }^{2}$

The intra-thoracic portion of the duct lies in a field that is less exposed to surgery, and its lesions in civil life are for the most part those of spontaneous rupture, which may occur when the duct is obstructed by the pressure of a malignant growth or by the chronic fibrosing inflammation due to filaria parasites. In such cases a collateral circulation is often fairly well developed before the rupture occurs, because the obstruction is slow in being established; and therefore the clinical picture differs from that caused by a wound suddenly severing a healthy duct which was the sole conduit for chyle from the visceral area to the venous system.

In the wounds of war-time the duct is no doubt often torn open by missiles that injure the chest; but its position is so closely related to that of the great vital vessels of the thorax that the bullet which can wound the duct is almost certain to kill by causing fatal hæmorrhage from the neighbouring blood-vessels.

Below the level of the fourth thoracic vertebra the duct is a target which a missile cannot reach without injuring in addition either the heart, the aorta, or the azygos veins. Above this level the duct passes outwards to the left, and it may take a path over the heads of the first three ribs or be displaced even further laterally. In this position the left mediastinal pleura comes into lateral or anterior relationship with it, while the origin of the left subclavian artery is immediately to the front. Here a ball may chance to pass between the vessels springing from the arch of the aorta and to cat the duct without injuring the great veins at the root of the neck.

The possible paths for such an injury may, perhaps, be several in number; but as a matter of experience, in each of the two cases quoted in this paper the track of the missile seems to have been the same, passing obliquely across the apex of the thorax, behind and under the subclavian artery and meeting the duct as it lay near the apex of the lung upon the vertebræ, or perhaps upon the heads of the ribs. This track is roughly parallel to the axis of the heart. It will permit the passage of a large projectile, such as a shrapnel ball, without associated fatal injuries. In our second case it appears likely that the shrapnel ball entering above the right clavicle had attained this path by passing through and splintering the body of a vertebra. It is a common and, indeed, it is the usual occurrence, for a missile to pass from side to side through the centrum of a vertebra without causing any symptoms of injury to the spinal cord. In the case of a double non-fatal hæmothorax, this is the path usually taken by the projectile concerned when it crosses in the upper two-thirds of the chest.

\section{Treatment.}

An intrathoracic wound of the duct is beyond the present skill of surgery for its repair. Case 1 shows that the fistula may close spontaneously in a few days. Increase of intrapleural pressure probably has some value in stopping the leak, for the chyle in the duct does not exert a high pressure, and therefore the volume of the effusion should be lessened by aspiration only when it is causing distress to the patient.

It is desirable that the prone position should be maintained in order to keep clots in contact with the apex of the chest. Fats in the food will increase the flow of chyle, but they will also help to give substance to any clot that may form. Whatever decision may be taken with regard to giving or withholding fats from the dietary, it is at any rate certain that they do not reach the patient's tissues so long as there is a complete leak from the duct, and therefore the sugars in the food must be increased in the attempt to maintain nutrition.

Case 2 was an example of a complete leak. Although the pleural cavity was infected, the patient showed a subnormal temperature that was below the limit of the thermometer, $95.4^{\circ} \mathrm{F}$, every morning on the last eight days of his life, while it was continually subnormal on the last three days before that on which he died. His body wasted away with extraordinary rapidity. He did not suffer from the hunger or from the intense thirst that has been described by other observers as being so conspicuous in cervical cases, where the patient survived with a leak for a longer period. Very notable in this case were the huge masses of curdy yellow clot that progressively filled the pleural cavity as the fluid part of the effusion was daily drained away. These formed so large a deposit as to give the impression that had the effusion been sterile, and had the patient survived owing to a spontaneous closure of the fistula, it would have become necessary later to open the thorax and remove the clot in order to give the lung a chance of expanding.

We are indebted to the various medical officers concerned for their kind permission to publish these clinical histories of cases that were directly under their care.

CASE 1.-Sergeant P. August 8th, 1916: Wounded by shrapnel ball, which entered the chest immediately above the outer third of the right clavicle and lodged under the skin at the very apex of the left axilla near the posterior axillary fold. No hæmoptysis. No vomiting or difficulty with swallowing. Eighteen hours after this injury the patient walked a mile, and there was no suggestion of any damage to the spinal cord, though the right brachial plexus was slightly injured.

Fourth day: Subcutaneous emphysema of left side. Signs of small Fourth day: Subcutaneous emphysema of left side. Signs of small
left effusion. Sixth day: Patient was sweating, cyanotic, and disleft effusion. Sixth day: Patient was sweating, cyanotic, and disthe left chest had increased retween $99^{\circ}$ and $100^{\circ}$. The effusion in sequence of this acumulation the medical officer in charge suspected sequence of this accumulation the medical officer in charge suspected sepsis. Seventh day : Chest explored. A pink, opaque, creamy fluid was obtained, the character of which led to its being regarded on naked-eje evidence as undoubtedly purulent. Rib resection was at
once performed. Much blood clot and a large quantity of apparently purulent fluid, estimated at about 80 ounces, were removed. Meantime the microscope had shown the exploration sample to consist only of blood and chyle, which separated on standing into a clean deposit of red cells below an opaque, creamy yellow fluid. Cultures subsequently proved this fluid to be completely sterile.

Eighth day: The resection wound was now completely closed by the surgeon in the hope that infection had not been introduced. Fleventh day: Physical signs of a large pneumothorax with complete collapse of left lung. Explored at left base; purulent fluid containing streptococei and a Gram-positive diphtheroid was found. The chest was opened again, air-tight drainage with a collecting flask boing at first employed. The pleural fluid received in this flask was now simply purulent. and the leakage of chyle had completely ceased. The drainage at first was not satisfactorily arranged and the lung failed to expand well. Thirtieth day : Transferred to England. Still a very large empsema cavit 5 , but patient was in good condition and had not lost flesh despite the heavy seccndary infections that had been implanted on the originally sterile pleura.

The subsequent history was not fully ascertained, but ten weeks after the wound the patient was reported to be doing well. 
CASE 2.-Sept. 15th, 1916: Wounded by fragment of shell which entered in the middle of the throat immediately below the thyroid cartilage. No exit wound. Fourth day: Admitted to base hospital. tint. Temperature $97 \cdot 4^{\circ} \mathrm{F}$; ; pulse 120 and weak. Heart displaced out to right nipple, and physical signs of complete pneumo-hæmothorax on the left side. From the general appearance of the patient at this early date, and from the absence of fever, it was thought air leak and not of a gas pneumothorax caused by infection. The chest was aspirated on the same day by Captain Thatcher, appearance of which at first suggested that it might have come appearance of which at first suggested that it might have come either from the stomach or from the thoracic duct. There was no standing in a test-tube a small deposit of blood cells fell out as a red standing in a test-tube a small deposit of blood cells fell out as a red
band at the bottom, leaving a greyish-yellow, opaque fluid above. band at the bottom, leaving a greyish-yellow, opaque fluid above.
Microscopically the fluid was found to be chyle, with an excessive Microscopically the fluid was found to be chyle, with an excessive
number of polymorphonuclear cells in the deposit and a few Gramnumber of polymorphonuclear cells in the deposit and a few Gram-
positive bacilli. Its appearance on first withdrawal and before the separation of the red cells by standing was very like that of an ordinary empyema fluid, though there was just enough difference in tint to raise a suspicion, in view of the experience from the preceding case, of its baving been derived from some abnormal source.

Fifth day: Bacteriological culture from the fiuid discovered a streptococcus as well as $B$. perfringens. The patient was still very ceding day were removed by aspiration. In the evening part of a rib was resected. More of the same fluid was found and the surgeon met with a yellow clotted mass in the pleural cavity which he thought to be prolapsed omentum and hastily replaced. Actually this mass was clotted chyle, which ought to have been removed.

Eighth day : Patient said that he felt worse. He was wasting with great rapidity and looked marasmic rather than septic. Pulse very feeble, 104 ; extremities cold, and temperature remaining deeply subnormal, below $95 \cdot 4^{\circ}$. There was a slight cyanotic flush on his cheeks. The patient's bed was almost soaked in chyle, which continued to pour when it was not blocked by yellow masses of clot that had a slightly rancid but otherwise inoffensive smell. He was drinking freely but without notable thirst, and had no appetite, though taking sugar and bananas fairly well. There had been no difficulty in swallowing at any time, and there was no hæmoptysis after the first day.

Ninth day : Heart still displaced to the right nipple, and still some cyanosis, while there was now a considerable amount of purulent sputum. In the hope of relleving the cardiac embarrassment a large drainage-tube was used with a big rubber fiap which was cemented on to the chest wall by a solution of dental rubber dissolved in
chloroform. This gave an air-tight junction and suction was then chloroform. This gave an air-tight junction and suction was then products being collected in an intermediate receiving flask. This saved the patient from the exhaustion which had been caused by the need for frequent redresssing when the chyle was allowed to leak out freely into the bed, and a large quantity of fluid was collected within the next 24 hours. But the apparatus failed to expand the lung because the tube was continually bing blocked by masses of coagulated chyle. Eleventh day: Patient had steadily been growing weaker and he died quietly. On this last day the temperature, which for the three preceding days had been below $95^{\circ} 4^{\circ}$. rose to $97^{\circ}$

preceding days had been below 95. Hose to $97^{\circ}$ : A small healed scar The autopsy showed as follows. Antry wound : A small healed scar
in the neck to the right of the middle line just below the level of the in the neck to the right of the middle line just below the level of the
cricoid. Beneath this lay a small collection of pus which had caused superficial necrosis of several of the cartilaginous rings of the trachea. The missile had entered the trachea and passed out from it again through a wound on the left side a little lower down. Both of the through a wound on the left side a little
wounds were septic but practically closed.

The track then ran behind the main vessels entering the neck, and perforated the pleural sac about $1 \frac{1}{2}$ inches from its apex. The smal piece of shell was found loose in the pleural sac, a position which it had reached after passing posteriorly through the upper lobe of the left lung and tearing a track along the upper surface of the lower lobe. The wound of the thoracic duct could not be found, but the track of the missile proved that this wound must have been in some position near the apex of the thorax that was surgically inaccessible.

The pleural eavity was filled with great masses of sour-smelling clot that resembled buttery yellow eurds, and were very light to handle. The clots contained innumerable large cavities, spaced like those of a Gruyère cheese, each of which held inoffensive gas and a little fluid Gruyere cheese, each of which held inoffensive gas and a tittle fluid
smelling of butyric acid. There was no appearance of pus to be fnund, smelling of butyric acid. There was no appearance of pus to be fnund,
nor any unpleasant odour suggesting the ordinary proteolytic products nor any unpleasant odour

The left lung was completely collapsed and showed the wound track described above. It had not re-expanded at all after rib resection, presumably because the drainage had been interfered with by the accumulated masses of clot. The heart still remained in a position
of extreme displacement to the right; there was no pericarditis. Bronchitis was evident in the right lung, but there were no areas of collapse.

Inoffensive gas (hydrogen and carbon dioxide) and simple organic acids are the ordinary products of the growth of pure $B$. perfringens on carbohydrates. No satisfactory analysis has yet been made by pathological chemists to show whether $B$. perfringens can effect the decomposition of fats, so that we are perforce content to record the changes position of fats, so that we are perforce content to record the changes explanation of them.

DONATIONS AND BEQUESTS.-By the will of the late Miss Emily H. Mortimer the Royal Isle of Wight Infirmary at Ryde and the Royal National Hospital for Consumption, Ventnor, will each receive $£ 1000$. - The late Mr. W. H. Sidley, whose estate has been valued at $£ 16,000$, left such sum as may be necessary for the endowment of a bed in the General Hospital, Birmingham, and the residue of his estate in equal shares to the Queen's Hospital and the General Hospital, Birmingham.

\section{THE MENACE OF MORPHINE TO CHINA.}

By WU LIEN-TEH (G. L. TUCK), M.D. CanTaB.,

PRESIDENT OF THE ChINESE NATIONAL medical association.

THE year 1917 will be historic as the one in which opium, the curse of China for 75 years, will be officially and finally banished from the country, for in this year the ten-year agreement made between Great Britain and China regarding its importation into China, including the last two seaports of Shanghai and Canton, will come to an end, so that even in the British Settlement of Shanghai the remaining opium shop will be closed by the month of March. The whole nation will rejoice at this happy termination of an awful vice, which once looked as if it might exterminate the Chinese race That the drug is scarce may be ascertained by the fact that the present price in Canton is at least $\$ 15$ per tael, with a tendency to rise. Except for some smuggling from Turkestan and Russia by way of Siberia very little opium will in future find its way into China, though the Government and Customs authorities will still have to exercise, in dealing with this enormously paying business, the greatest vigilance over unscrupulous people.

\section{Morphine Statistios: British and Japanese Traders in Morphine.}

I am afraid we cannot be so sanguine with regard to morphine, for up to the end of last year all statistics point to increased importation into China. The supply of morphine comes mainly from two firms in Edinburgh and one firm in London. The following table shows the declared exports of morphine from Great Britain alone :-

$$
\begin{aligned}
& 1912 \quad \ldots . .276,572 \text { ounces, equal in weight to } 7 \frac{1}{2} \text { tons. } \\
& 1913 \quad \cdots \cdots . \quad 406,154
\end{aligned}
$$

It is estimated that the exports in the years 1915 and 1916 are at least 600,000 ounces for each year, equal to over 16 tons. Moreover, the normal importation of opium into Japan for medicinal purposes is only 10 chests a year, but the importation of morphine into that country in 1911 was $1 \frac{1}{2}$ tons; in 1914 this had risen to 12 tons-that is, 1 ton a month. There is a large firm in Japan which acts as agent for the manufacturing firm in London. In 1913 alone this agent in Japan imported $2 \frac{1}{2}$ tons of morphine by registered post via Siberia. The two other British firms exported 2 ton by the same method, and 13 tons came from Germany, making a total of $6 \frac{1}{4}$ tons in 1913. So far it ha been ascertained that neither Japan nor Germany has got the necessary plant to manufacture morphine on any large scale, and the alkaloid has come mostly from firms in Great Britain. Once arrived in Japan the morphine is usually made up into small packets or placed into smal bottles, labelled in different ways-e.g., morphine, "whit powder," "soothing stuff," "dreamland elixir," \&c., and exported openly or smuggled secretly into China by way of Dalny, Antung, and Formosa. Almost every Japanese drug dealer or pedlar in Manchuria sells it in one form or another, and does so with impunity, because no Japanese can be arrested without complaint being first lodged at the Consulate. From these Japanese agents and sub-agents the drug may be passed on to disreputable Chinese who frequent the coolie depôts and inject a solution, usually very dirty, with hypodermic syringe which may be made with glass, metal, or even bamboo. Rigorous imprisonment for two years is a common sentence for Chinese found with morphine in their possession, but the principal culprits often escape punishment.

The morphine habit was first brought into Ohina by returned Swatow emigrants from Singapore and spread to other parts of Fukien. During my five years residence in Manchuria I have seen terrible havoc wrought upon the population by this drug. More than half of our regular jailbirds there show needle signs over their bodies, professional beggars found in the streets of Harbin, Kirin, Changchun and Tsitsihar are victims of the habit, and thousands of poor people die in the large cities during the winter months, partly from cold but principally from inability to work on account of their morphine habits. From all sources I learn that the evil is spreading rapidly, and it is worse than opium

I A paper read before the Joint Medical Conference, Canton, 